\section{Estudo \\ CoDebate}

em Testão

Planejamento
Revista Estudo \& Debate, Lajeado, v. 26, n. 2, 2019. ISSN 1983-036X

DOI: http://dx.doi.org/10.22410/issn.1983-036X.v26i2a2019.2056

\title{
O CONSELHO REGIONAL DE BIOLOGIA DA 3a REGIÁO: A ART E A INSERÇÃO DO BIÓLOGO NO MERCADO DE TRABALHO
}

\author{
Daniella Randazzo de Azevedo Braga ${ }^{1}$, Carlos Honorato Schuch dos Santos ${ }^{2}$
}

\begin{abstract}
Resumo: Este trabalho tratou da evolução cronológica da Anotação de Responsabilidade Técnica - ART no CRBio-03, da inserçáo do Biólogo no mercado de trabalho, através dos dispositivos legais editados pelo CFBio, e da estruturação do setor e sistema de fiscalização no Conselho Regional. Por seu caráter unitário, pode ser considerado um estudo de caso e, também, uma pesquisa exploratória-descritiva, pois analisou dados primários do órgão com foco do trabalho, procurando descobrir a existência de relaçôes entre esses dados. Esteve apoiado em documentos e bibliografia. Após a análise, concluiu-se, que a criação do CRBio-03 e a implementação da ART, com seu aperfeiçoamento para o sistema on-line, foram determinantes para o atendimento dos interesses dos Biólogos e empresas ligadas à biologia. A estruturação do setor e do sistema de fiscalização, provavelmente, foram fatores que contribuíram para uma fiscalização mais efetiva da profissão e para uma consequente melhoria na qualidade dos serviços prestados à sociedade.
\end{abstract}

Palavras-chave: Biólogo. Conselho Profissional. Anotação de Responsabilidade Técnica. Atuação profissional.

\section{REGIONAL COUNSEL OF BIOLOGY OF THE 3RD REGION: THE ART AND THE INSERTION OF THE BIOLOGIST IN THE MARKETPLACE}

\begin{abstract}
This work handled the chronological evolution of the Technical Term of Responsibility (ART) in the CRBio-03, the insertion of the Biologist in the marketplace through legal devices edited by the CFBio, and the structuring of the field and of the inspection system in the Regional Counsel. For its unitary character it can be considered a case study as well as an exploratory-descriptive research, for it analyzed primary data of the body studied in this work aiming at finding the existence of relation between the data. The study was done through documents and bibliography. After the analysis it was concluded that the creation of the CRBio-03 and the implementing of the ART with its perfecting to an online system were determinants for meeting the interests of Biologists and of Biology-related companies. The structuring of the field and of its inspection system were likely factors that contributed to a more effective inspection of the profession and a consequent improvement in the quality of the services provided to society.
\end{abstract}

Keywords: Biologist. Professional Counsel. Technical Term of Responsibility. Professional Performance.

1 Especialista em Educação Ambiental, 1999 (UNILASALLE). Bacharel em Ciências com Habilitação em Biologia - Fitoquímica, 1992 (UNISINOS).

2 Doutor em Engenharia da Produção, 1998 (UFSC). Mestre em Administração, 1992, (UFRGS). Graduado em Administração Pública, 1992 (UFRGS). 


\section{Introdução}

A Lei no 6.684, de 3 de setembro de 1979, regulamentou a profissão de Biólogo e de Biomédico e criou o Conselho Federal de Biologia e Biomedicina (CFBB) e os Conselhos Regionais de Biologia e Biomedicina (CRBB). Em 1982, através da Lei no 7.017, de 30 de agosto de 1982, foram desmembrados os Conselhos Federal e Regionais de Biomedicina e de Biologia. Posteriormente, em 1983, através do Decreto no 88.438, de 28 de junho de 1983, foi regulamentado o exercício da profissão de Biólogo, de acordo com a Lei no 6.684 , de 3 de setembro de 1979 , e em conformidade com a alteraçáo estabelecida pela Lei no 7.017 de 30 de agosto de 1982 (CONSELHO FEDERAL DE BIOLOGIA, 2018).

Os conselhos de fiscalização profissional foram criados por lei e são dotados de personalidade de direito público, com autonomia administrativa, patrimonial e financeira, caracterizados como autarquias (COSTA; VALENTE, 2008).

Para o atendimento de suas funçôes de orientação, disciplina e fiscalização do exercício profissional, alguns conselhos de fiscalização fazem o controle das atividades técnicas através da Anotação de Responsabilidade Técnica (ART). No Conselho Regional de Biologia da $3^{a}$ Região (CRBio-03), esse instrumento de ação tornou-se uma ferramenta ágil, no sentido de informar permanentemente as atividades desempenhadas, bem como dados atualizados a respeito da atuação profissional.

Esse instrumento de aferição do exercício profissional e balizador da fiscalização prospectou a inserção do Biólogo no mercado de trabalho e permitiu maior transparência no desempenho das atividades técnicas, sendo, portanto, benéfico para a sociedade.

O presente artigo analisa a evolução histórica da ART no CRBio-03, a partir da instituição da mesma pelo Conselho Federal de Biologia (CFBio), da inserção do Biólogo no mercado de trabalho e da estruturação do setor e do sistema de fiscalização da atividade profissional como forma de assegurar e defender os interesses da profissão e da sociedade.

\section{Referencial Teórico}

A revisão bibliográfica e a análise de variáveis constituem-se na base teórica que fundamentou o trabalho aqui proposto. Para tanto, buscou-se caracterizar: a) a criação do CRBio-03, em termos de sua abraqngência geográfica e atribuiçôes; b) a ART, com suas funçóes e modalidades; e c) os procedimentos de fiscalização, com sua estrutura e funcionamento.

\subsection{Conselho Regional de Biologia da 3a Regiáo (CRB-3/CRBio-03)}

Os conselhos de fiscalização profissional constituem desmembramentos legais da União, possuindo atribuições próprias da ação estatal (COSTA; VALENTE, 2008). Além do marco legal, os conselhos funcionam como um regulador para a própria atividade, sendo, dessa forma, uma garantia, para a sociedade, de que aqueles profissionais registrados no Conselho estão, teoricamente, habilitados para executar suas funçóes.

Através da Resolução CFB no 006, de 6 de novembro de 1986, o Conselho Federal de Biologia (CFB) criou, além de outros quatro, o Conselho Regional de Biologia (CRB-3), 
com sede em Porto Alegre e com a função legal de fiscalizar o exercício profissional na área de sua jurisdição, no caso os estados do Rio Grande do Sul, Santa Catarina e Paraná. O Conselho Regional de Biologia constitui-se em uma Autarquia Federal, de Direito Público, tendo como objetivo básico fiscalizar, orientar e promover o exercício da profissão de biólogo. (CONSELHO REGIONAL DE BIOLOGIA, c2018)

O CRB-3, que iniciou sua trajetória em junho de 1987 (NEVES et al., 2011), adotou posteriormente a sigla CRBio-03, uma vez que o Conselho de Biblioteconomia profissão regulamentada em 1962 (BRASIL, 1962), já usava a sigla CRB para os Conselhos Regionais e CFB para o Conselho Federal. Em 1999, através da Resolução CFBio no 7 , de 11 de junho de 1999, as siglas do Conselho (CFB e CRB), foram, entâo, alteradas para CFBio e CRBio.

Com o passar dos anos, apesar da proximidade territorial entre os três estados, o CRBio-03. por entender que a Delegacia do Paraná apresentava viabilidade jurídica, financeira e estrutura física e de recursos humanos, encaminhou ao CFBio a solicitação de seu desmembramento, sendo aprovado através da Resoluçáo CFBio no 62, de 11 de junho de 2005: "Fica criado o Conselho Regional de Biologia da 7a Regiáo - CRBio-07, e dá outras providências" (CONSELHO FEDERAL DE BIOLOGIA, 2005). A partir de janeiro 2006, tomou posse, então, a diretoria do CRBio-07 (NEVES et al., 2011), e o CRBio-03 ficou com, e detém até hoje, a jurisdição dos outros dois Estados.

\subsection{Anotaçáo de Responsabilidade Técnica (ART)}

A Resoluçáo CFB no 10, de 11 de maio de 1988, considerando as atividades realizadas por profissionais biólogos, legalmente habilitados, definiu a capacidade técnica destes e das pessoas jurídicas ligadas às Ciências Biológicas. Essa capacidade foi atrelada à graduação acadêmica, considerando o currículo efetivamente realizado e a experiência profissional. A ART é um documento que certifica esta capacidade.

As atividades de prestação de serviço, como estudo, projeto, pesquisa, orientação, direçáo, assessoria, consultoria, perícia, experimentação, levantamento de dados, parecer, relatório, laudo técnico, inventário, planejamento, avaliação, arbitramentos, planos de gestâo e quaisquer outros serviços na área de biologia ou a ela ligados, realizados por pessoa física, ficaram sujeitos à ART. Esse instrumento de ação dos biólogos foi instituído pela Resoluçáo CFB no 5, de 2 de setembro de 1996 (CONSELHO FEDERAL DE BIOLOGIA, 1996), e disciplinada, posteriormente, pela Resoluçáo CFBio no 11, de 05 de julho de 2003. Com essa Resolução, ficou acrescida à modalidade de ART de ocupação de cargo ou função (CONSELHO FEDERAL DE BIOLOGIA, 2003, documento eletrônico não paginado):

Art. 20 Ficam também sujeitas à ART as atividades profissionais que dizem respeito à proposição, execução, coordenação, supervisão e orientação de estudos, projetos, pesquisas, assessorias, consultorias, perícias, pareceres e laudos técnicos, fiscalização e quaisquer outras atividades nas áreas das Ciências Biológicas ou a elas ligadas, desenvolvidas em caráter contínuo por meio de contrato de trabalho ou vínculo de outra natureza, nas seguintes Modalidades de Ocupação de cargo ou função:

I - cargo ou função técnica pelo desempenho de atividades citadas no caput deste artigo, independente da denominação do cargo: Biólogo, Biologista, Professor, Técnico de Nível 
Superior, Tecnologista ou Laboratorista de Nível Superior, Perito, Analista, Agente e/ou Fiscal, Pesquisador, Responsável Técnico, entre outros;

II - cargo administrativo ou gerencial;

III - cargo comissionado.

A instituição da ART foi, para o CRBio-03, um marco importante para a estruturação do serviço de fiscalização, previsto no Manual de Orientação e Fiscalização do Exercício Profissional (MOFEP) (Resolução CFB no 11, de 19 de novembro de 1991) (CONSELHO FEDERAL DE BIOLOGIA, 1991) e estabelecido pela Resolução CFBio no 284, de 20 de outubro de 2012 (CONSELHO FEDERAL DE BIOLOGIA, 2012) (que determinou os procedimentos de fiscalização, definiu competências e instituiu o MOFEP atual.

\subsection{Procedimentos de fiscalizaçáo}

O MOFEP, instituído pelo CFBio através das Resoluçóes CFB no 11, de 19 de novembro de 1991 (revogada), e Resolução CFBio no 284, de 20 de outubro de 2012 balizou atribuiçôes, estrutura e funcionamento da fiscalização do exercício profissional.

No ano de 1997, o CRBio-03, em atendimento à legislaçáo vigente, contratou, por meio de concurso público, sua primeira Fiscal Bióloga - sendo esse, na ocasião, o único Regional com tal recurso humano, o que representou um salto de qualidade e maior agilidade no atendimento à fiscalização da profissão. A fiscalização implantada pelo CRBio-03 serviu de modelo para os demais CRBios (NEVES et al., 2011). Iniciou-se, então, a estruturação do setor de fiscalização, e os biólogos que atuavam na regiáo Sul começaram a emitir suas ARTs.

Os MOFEPs estabeleceram as competências e atribuições do Agente Fiscal/Fiscal no desempenho de suas funções de orientar e fiscalizar o exercício profissional de biólogo por meio da realização de vistorias e elaboração dos respectivos relatórios de vistoria. Esses documentos dão início ao processo fiscalizatório de biólogos e pessoas jurídicas ligadas às Ciências Biológicas.

\section{Metodologia}

$\mathrm{O}$ presente artigo pode ser considerado um estudo de caso, pois preservou-se "o caráter unitário do objeto estudado" (GIL, 2004, p. 54). Como o objetivo foi analisar dados primários do próprio órgão foco, o trabalho pode, também, ser categorizado como exploratório-descritivo, pois visou "descobrir a existência de associaçóes entre variáveis" (GIL, 2004, p.42). O trabalho apoiou-se, principalmente, em legislação e publicaçôes, conforme constam nas Referências, logo sua base é documental.

Em relação às etapas, inicialmente procurou-se contextualizar a implementação da ART no CRBio-03. Na sequência, buscou-se evidenciar a inserção do profissional biólogo no mercado de trabalho no sul do país. Na última etapa, lançou-se luz sobre o setor e o sistema de fiscalizaçáo. Para isso, foram trabalhados dados oriundos do banco de dados do CRBio-03 referentes aos números de registro de biólogos ativos, de ARTs, de fiscais e de agentes fiscais no período de 2010 a 2017. 


\section{Resultados e análise}

Foram abordados os temas da evolução do exercício profissional do biólogo no CRBio-03, o mercado de trabalho e os dados de ARTs, registros de pessoas físicas e número de fiscais/agentes fiscais do Regional. Portanto, são analisados diferentes aspectos da evolução do exercício profissional do biólogo e sua inserção no mercado de trabalho.

\subsection{Evolução do Exercício Profissional do Biólogo no CRBio-03}

A ART passou a fazer parte do contexto do CRBio-03 a partir de março de 1997. Desde então, os biólogos puderam dar legitimidade aos seus estudos e trabalhos através do preenchimento de formulário próprio, onde eram anotados as atividades e serviços e definidos, para efeito legal, os responsáveis técnicos. A partir de 2003, além da ART por atividade e prestação de serviços, foi criada a ART de Ocupação de cargo ou função. As ARTs constituíram, para todos os fins, o Acervo Técnico do biólogo.

De 1997 até início de 2007, as ARTs eram preenchidas manualmente, em formulário próprio, avaliadas e autorizadas pelo setor de fiscalização do Conselho. Em meados de 2007, iniciou-se a efetivação das ARTs pela internet (on-line). O banco de dados do CRBio-03 registrou, de 1997 a 2017, um total de 192.021 ARTs nas modalidades de prestação de serviço e ocupação de cargo ou função (Gráfico 1).

Gráfico 1 - Número de ARTs por ano no CRBio-03 - período de 1997 a 2017

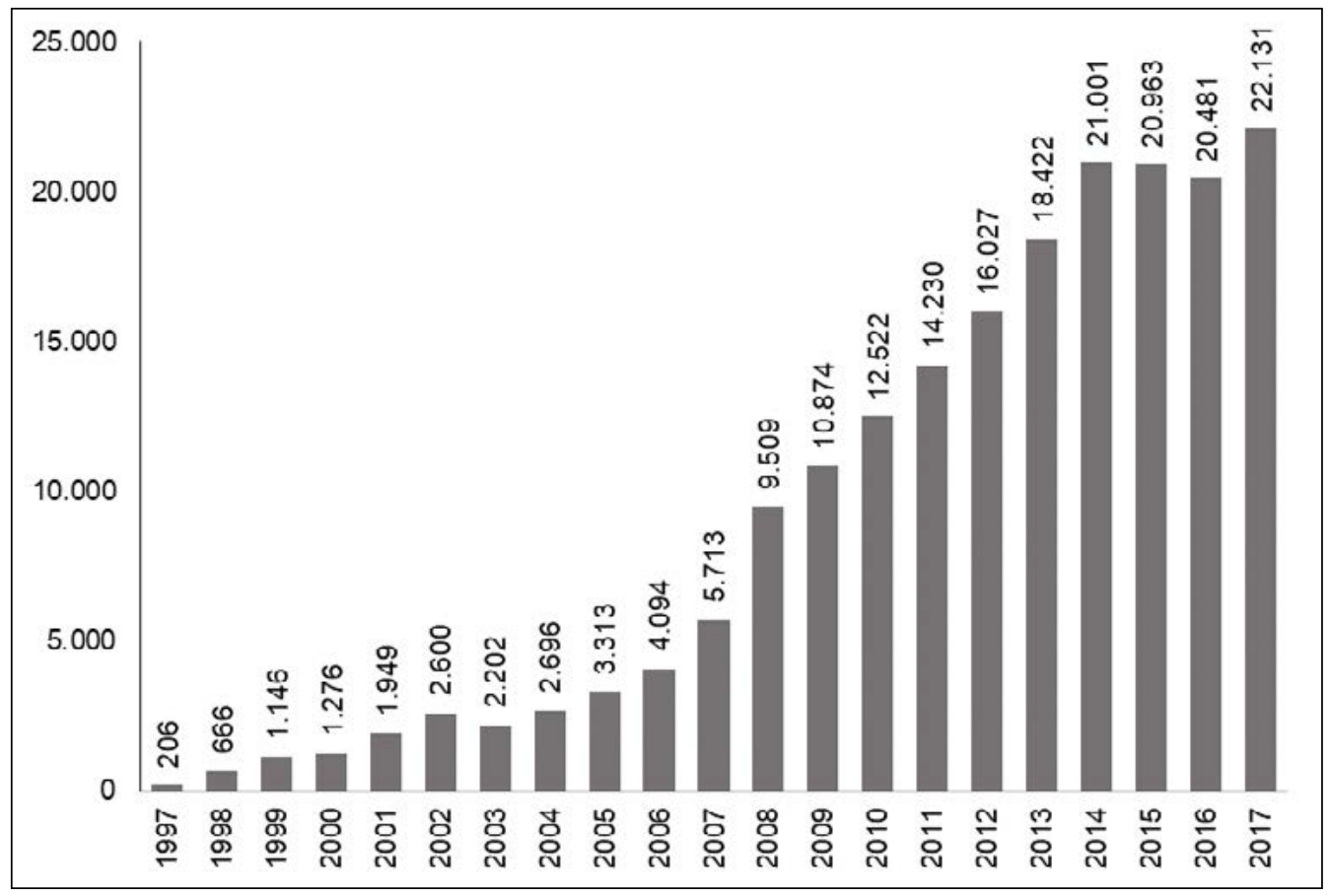

Fonte: Autores (2018). 
$\mathrm{Na}$ evolução cronológica das ARTs do CRBio-03 (Gráfico 1), ao longo do período considerado, pode-se perceber dois momentos (tendências de crescimento): um, nos primeiros dez anos da sua implantação, isto é, de 1997 a 2007, quando as ARTs eram manuais, e a outro, nos dez anos seguintes, de 2007, quando teve início no Regional a ART on-line, até o ano de 2017.

A implementação da ART on-line e o uso desse sistema pelos biólogos atuantes no Rio Grande do Sul e em Santa Catarina mostrou-se um fator diferenciado na curva de crescimento quanto ao número de documentos emitidos. Nos dez primeiros anos considerados, somaram-se 26.134 ARTs manuais e, nos dez anos seguintes, foram totalizadas 165.887 ARTs on-line.

\subsection{Mercado de trabalho}

$\mathrm{O}$ incremento da ART on-line representou um avanço positivo para os biólogos, pois passaram a ter acesso mais rápido ao documento quando contratados. Com isso, houve uma inserção mais igualitária, quando comparado com outros profissionais, no mercado de trabalho.

O CFBio, considerando o currículo efetivamente realizado pelo biólogo, o estágio do desenvolvimento científico e tecnológico e a evolução do mercado de trabalho, publicou em 2010 a Resolução CFBio no 227 (CONSELHO FEDERAL DE BIOLOGIA, 2010), dispondo sobre a regulamentação das Atividades Profissionais e das Áreas de Atuação do Biólogo em Meio Ambiente e Biodiversidade, Saúde e, Biotecnologia e Produção, para efeito de fiscalização do exercício profissional.

O CFBio editou resoluções específicas para diferentes áreas no intuito de estabelecer diretrizes para a atuação dos biólogos em atividades e empreendimentos públicos, privados e do terceiro setor, com necessidade de licenciamento ambiental, e por força de lei; do mesmo modo, para atividades de planejamento, gerenciamento, análise e auditorias ambientais. As Resoluções CFBio no 350, de 10 de outubro de 2014, sobre atuação do biólogo em Licenciamento Ambiental, e a Resoluçáo CFBio no 374, de 12 de junho de 2015, sobre a atuação do biólogo em Gestão Ambiental, deram maior suporte à atuação dos biólogos na área ambiental (CONSELHO FEDERAL DE BIOLOGIA, 2015a), corroborando com o disposto no artigo 225 da Constituição Federal (BRASIL, 2015, p. 233), que garante:

Art. 225 Todos têm direito ao meio ambiente ecologicamente equilibrado, bem de uso comum do povo e essencial à sadia qualidade de vida, impondo-se ao Poder Público e à coletividade o dever de defendê-lo e preservá-lo para as presentes e futuras geraçóes;

Ainda nesse sentido, e no intuito de fortalecer a atuação dos biólogos em áreas de sombreamento, com outras profissóes igualmente habilitadas, o CFBio publicou as seguintes resoluçóes: Resoluçáo CFBio no 384, de 12 de dezembro de 2015, que "Dispóe sobre a atuação do Biólogo no Controle de Vetores e Pragas Sinantrópicas" (CONSELHO FEDERAL DE BIOLOGIA, 2015b), e a Resoluçáo CFBio no 449, de 23 de outubro de 2017 (CONSELHO FEDERAL DE BIOLOGIA, 2017), que "Dispóe sobre as diretrizes para a atuação do Biólogo em Paisagismo". 
A Constituição Federal, já no início, em seu artigo 50 (BRASIL, 2015, p. 5), institui:

Art. $5^{\circ}$ Todos são iguais perante a lei, sem distinção de qualquer natureza, garantindo-se aos brasileiros e aos estrangeiros residentes no País a inviolabilidade do direito à vida, à liberdade, à igualdade, à segurança e à propriedade, nos termos seguintes: [...] XIII - é livre o exercício de qualquer trabalho, ofício ou profissão, atendidas as qualificaçóes profissionais que a lei estabelecer;

Essas publicaçóes auxiliam os biólogos nas definiçóes de atividades em cada área/ subárea de atuação, pois as diretrizes são norteadoras em nomenclaturas e correlaçóes com outras legislações referentes ao assunto.

Cabe ressaltar que até o ano de 2003 as ARTs correspondiam exclusivamente à modalidade de prestação de serviço. A partir de 2004, passaram a corresponder ao somatório de ARTs de prestação de serviço e de ocupação de cargo ou função (Gráfico 1).

O número de ARTs no CRBio-03, em Meio Ambiente e Biodiversidade, é fortemente discrepante em relação às ARTs das demais áreas de atuação. As atividades desempenhadas por biólogos nas áreas da Saúde, da Biotecnologia e da Produção são, na grande maioria, atividades de caráter contínuo, demandando uma única ART para a atividade, neste caso, ART de ocupaçáo de cargo ou função. O que é diferente para as atividades em Meio Ambiente e Biodiversidade é que a grande maioria das ARTs são de prestação de serviços episódicos. Essas são efetuadas a cada trabalho executado (Gráfico 2).

Gráfico 2 - Número/Percentual de ARTs na área de Meio Ambiente e em outras áreas período de 2010 a 2017

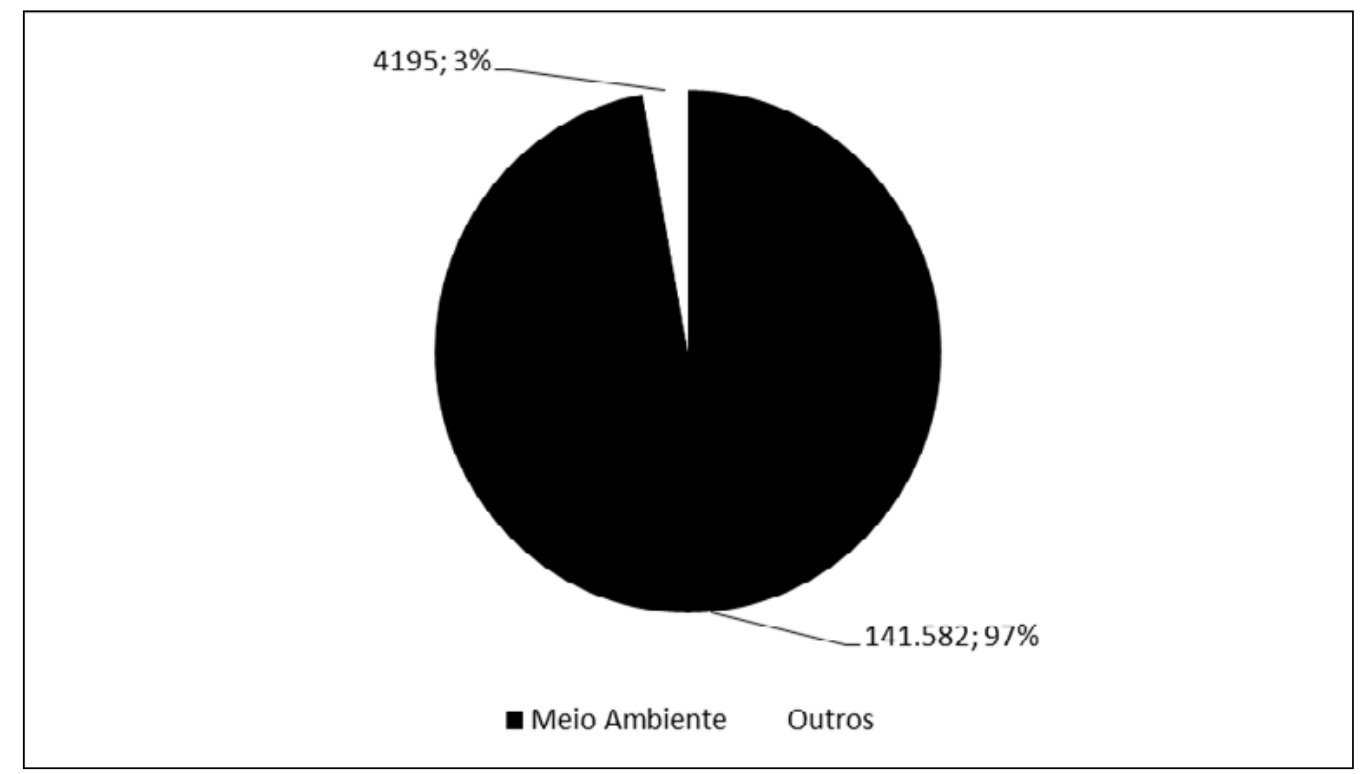

Fonte: Autores (2018). 
A comparação do número de ARTs efetuadas no CRBio-03 em meio ambiente, em relação às outras áreas, no período de 2010 a 2017, mostra uma diferença perceptível (Gráfico 2). A área de meio ambiente corresponde a $97 \%$ das ARTs efetuadas. Pode-se apontar duas razóes para tal diferença: a) a principal é a origem da profissão do biólogo - o estudo e a pesquisa da natureza, as questóes voltadas à fauna, à flora e suas interaçóes - desde quando os mesmos eram denominados naturalistas; e, b) a outra, já mencionada, está relacionada à prestação dos serviços de Meio Ambiente e Biodiversidade. Essas últimas são, normalmente, ARTs para prestação de serviço, enquanto nas áreas da Saúde e de Biotecnologia e Produçáo são, normalmente, ARTs de ocupação de cargo ou função.

Quando se foca em biólogos ativos, que são os profissionais com situação cadastral ativa, pode-se perceber um crescimento homogêneo no registro profissional de Biólogos, no CRBio-03, no período analisado (Gráfico 3). Em 2010, por exemplo, havia 5.053 profissionais ativos, e, em 2017, o número era de 8.334, mostrando um crescimento que se pode considerar como uniforme, isto é, uma média de 500 registros/ano de 2010 a 2016 . A exceção foi no ano de 2017, quando o número de registrados foi de 277.

Gráfico 3 - Número de Biólogos ativos - período de 2010 a 2017.

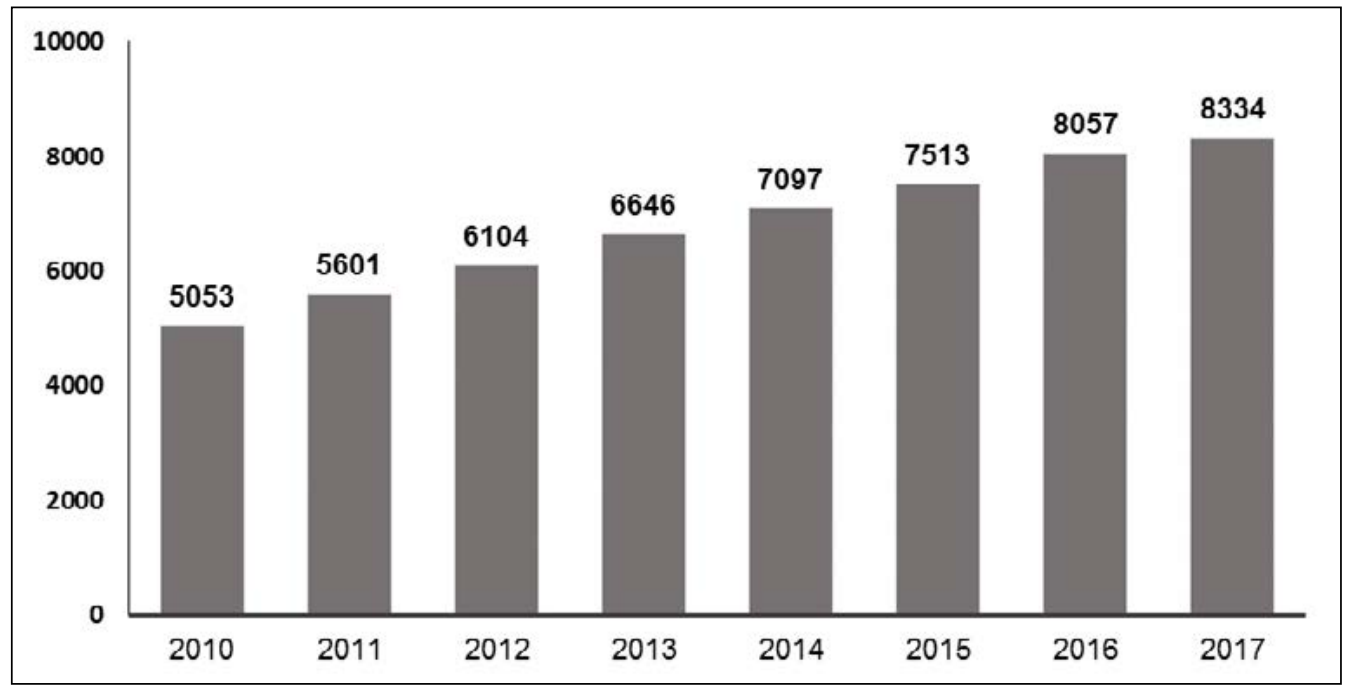

Fonte: Autores (2018).

\subsection{Setor de Fiscalizaçáo}

Em 1997 iniciou-se a estruturação do setor de fiscalização no CRBio-03 através da contratação do primeiro fiscal. No sentido de atender sua função fim, orientação e fiscalização do exercício das atividades do biólogo e Pessoa Jurídica, o Regional, desde então, tem mantido um corpo permanente de Fiscais (biólogos) e/ou Agentes Fiscais (nível médio) com as respectivas atribuições.

As fiscalizaçóes foram sempre efetuadas por meio de visitas/vistorias a órgão públicos e privados, sejam eles prefeituras municipais, hospitais, laboratórios, universidades, órgãos 
de fiscalização municipal, estadual e federal, empresas de consultoria e outros, onde é pertinente a atuação de profissional biólogo.

Para efetuar as fiscalizaçóes, desde 1997 até hoje, tem sido utilizado transporte público. No ano de 2017, o CRBio-03 passou a utilizar também um automóvel locado para agilizar o desempenho nas fiscalizaçóes.

O número de fiscais/agentes fiscais atuando durante o ano inteiro, diferente do número de profissionais, apresentou um comportamento não uniforme (Gráfico 4). Nos casos em que houve fiscal ou agente fiscal atuando na metade do tempo (meio ano), foi considerado meio fiscal/agente fiscal.

Gráfico 4 - Número de Fiscais/Agentes Fiscais - período de 2010 a 2017

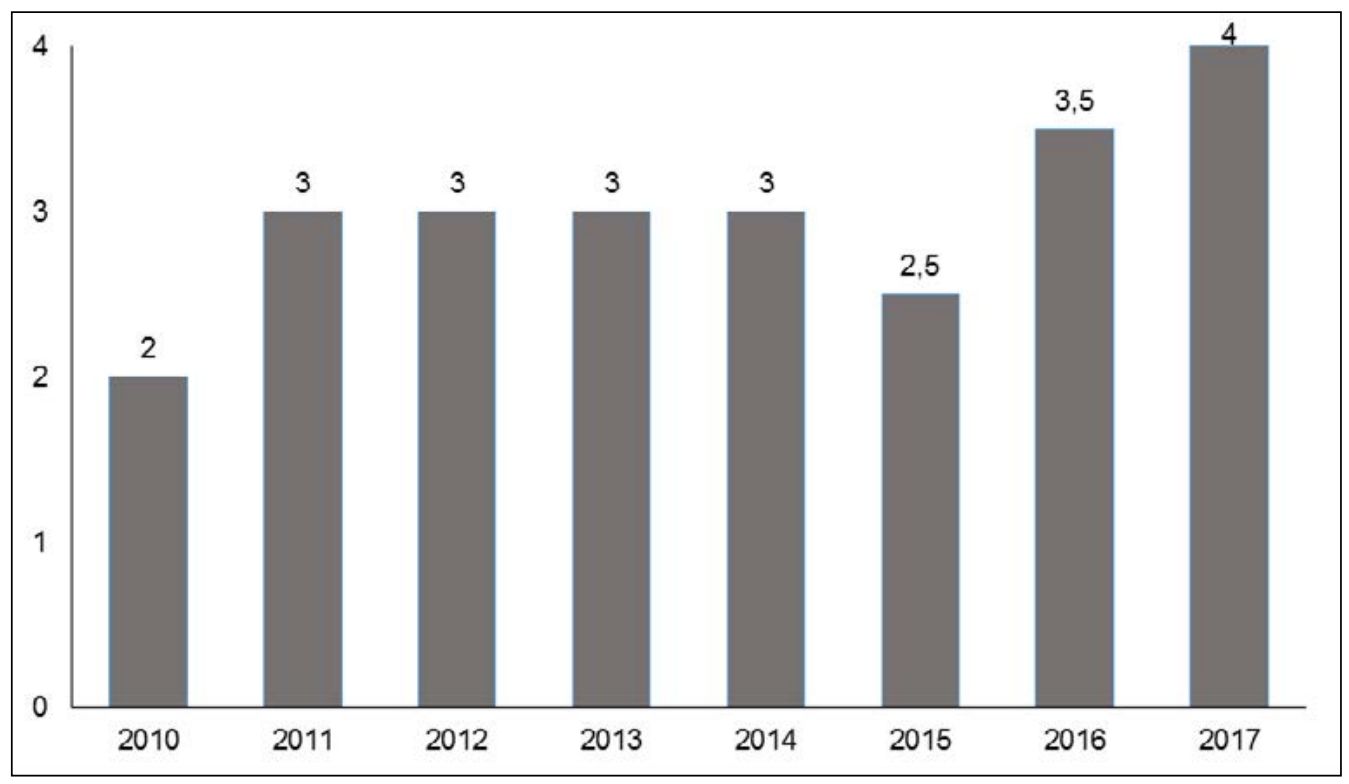

Fonte: Autores (2018).

No ano de 2016, por problemas de conflitos entre membros da gestáo do Conselho, as fiscalizaçōes foram efetuadas em dois terços do ano (oito meses). Esses eventos, no entanto, não são suficientes para justificar o comportamento histórico, embora não se possa subestimar a sua influência.

A análise do número de ARTs (Gráfico 5) no período de 2010 a 2014 mostra um crescimento positivo, sendo que nos anos 2015 e 2016 houve um decréscimo em relação aos anos anteriores, voltando, novamente, a mostrar-se positivo em 2017, inclusive numericamente superior a 2014. 
Gráfico 5 - Número de ARTs por ano - período de 2010 a 2017

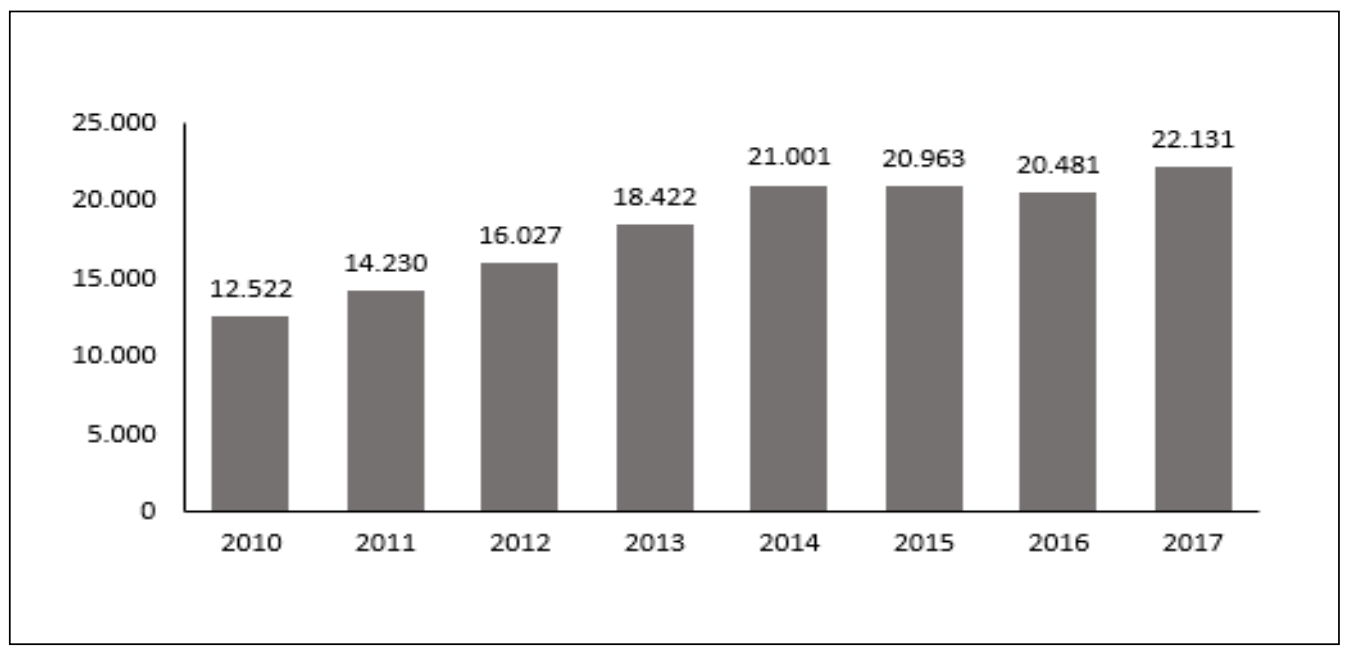

Fonte: Autores (2018).

Muitos fatores podem influenciar na atividade profissional de uma categoria, como: mercado de trabalho, economia, legislaçóes, número de profissionais atuando, etc. No caso do CRBio-03, é possível verificar um crescimento homogêneo no número de registrados (pessoas físicas) de 2010 a 2017 (Gráfico 3). Porém, nesse mesmo período, as ARTs efetuadas tiveram um amortecimento em número de crescimento de 2014 a 2016, e depois um pequeno incremento em 2017 (Gráfico 5).

A diminuição do número de fiscais/agentes fiscais no ano de 2015 e a diminuição do tempo de fiscalização em 2016 podem ter sido fatores que influenciaram no amortecimento do crescimento do número de ARTs nesses anos. $\mathrm{O}$ aumento do número de fiscais/agentes fiscais e o início do uso do carro em fiscalizaçóes pode ter tido influência no pequeno incremento no número de ARTs ocorrido em 2017.

$\mathrm{O}$ que se pode perceber, analisando o conjunto de informaçóes, é que houve crescimento quase linear e os incrementos foram significativos. Tem-se, portanto, que o CRBio-03, de alguma forma, tem cumprido sua função legal, bem como sua função de fiscalizar a atuação e a qualidade dos serviços dos profissionais biólogos.

\section{Conclusáo}

A criaçáo do CRBio-03 foi determinante para o atendimento dos interesses dos biólogos e pessoas jurídicas ligadas à biologia e para a qualidade dos serviços prestados à sociedade.

Com a implementação da ART, deu-se a estruturação do setor de fiscalização no CRBio-03 e a contratação de funcionários com a tarefa específica de orientar e fiscalizar os biólogos atuantes no sul do país. Legitimou-se o exercício do profissional do biólogo e sua inserção no mercado de trabalho. 
A implantação do sistema de fiscalização por meio da ART on-line, provavelmente, constituiu-se em um dos fatores que têm contribuído positivamente no sentido de uma inserção mais igualitária do biólogo, em relação a outros profissionais, no mercado de trabalho, bem como uma maior facilidade e agilidade na fiscalização do exercício profissional da categoria.

\section{Referências}

BRASIL. [Constituiçẫo (1988)]. Constituiçáo da República Federativa do Brasil: de 5 de outubro de 1988. Organizado por: Alexandre de Moraes. 41. ed. Sáo Paulo: Atlas, 2015. (Coleção de Manuais de Legislação Atlas).

BRASIL. Lei no 4.084, de 30 de junho de 1962. Dispõe sôbre a profissão de bibliotecário e regula seu exercício. Disponível em: <http://www.planalto.gov.br/ccivil_03/ LEIS/1950-1969/L4084.htm>. Acesso em: 03 jul. 2018.

BRASIL. Decreto no 88.438, de 28 de junho de 1983. Dispóe sobre a regulamentação do exercício da profissáo de Biólogo, de acordo com a Lei no 6.684, de 3 de setembro de 1979 e de conformidade com a alteraçáo estabelecida pela Lei no 7.017 de 30 de agosto de 1982. Disponível em: <http://www.planalto.gov.br/ccivil_03/decreto/1980-1989/ D88438.htm>. Acesso em: 03 jul. 2018.

CONSELHO FEDERAL DE BIOLOGIA. Histórico. [2018]. Disponível em: http:// www.cfbio.gov.br/historico. Acesso em: 03 jul. 2018

CONSELHO FEDERAL DE BIOLOGIA. Lei no 6.684, de 3 de setembro de 1979. Regulamenta as profissões de Biólogo e de Biomédico, cria o Conselho Federal e os Conselhos Regionais de Biologia e Biomedicina, e dá outras providências. Disponível em: <http://www.cfbio.gov.br/artigos/LEI-N\%C2\%BA-6684-DE-3-DE-SETEMBRODE-1979>. Acesso em: 03 jul. 2018.

CONSELHO FEDERAL DE BIOLOGIA. Lei no 7.017, de 30 de agosto de 1982. Dispóe sobre o desmembramento dos Conselhos Federal e Regionais de Biomedicina e de Biologia. Disponível em: <http://www.cfbio.gov.br/artigos/LEI-No-7017-DE-30-DEAGOSTO-DE-1982>. Acesso em: 03 jul. 2018.

CONSELHO FEDERAL DE BIOLOGIA. Resoluçáo CFB no 006, de 6 de novembro de 1986. Ficam criados cinco Conselhos Regionais de Biologia. Disponível em: <https:// www.crbio01.gov.br/media/view/2016/01/resoluc_a_o_cfbio_n_1986-06_-_cria_os_ cinco_regionais_78.pdf>. Acesso em: 01 nov. 2018.

CONSELHO FEDERAL DE BIOLOGIA. Resoluçáo CFB no 10, de 11 de maio de 1988. Capacidade Técnica do Biólogo... [Revogada]. 
CONSELHO FEDERAL DE BIOLOGIA. Resolução CFB no 11, de 19 de novembro de 1991. Cria as COFEPs - Comissões de Orientação e Fiscalização do Exercício Profissional no âmbito dos CRBs, define competências e institui o Manual de Orientação e Fiscalização do Exercício Profissional - MOFEP. 1991. [Revogada]. Disponível em: <http://www.cfbio.gov.br/artigos/RESOLUcaO-CFBio-N\%C2\%BA-11-DE-19-DENOVEMBRO-DE-1991>. Acesso em: 02 nov 2018.

CONSELHO FEDERAL DE BIOLOGIA. Resoluçáo CFB no 5, de 2 de setembro de 1996. Institui a regulamentação para Concessão da Anotação de Responsabilidade Técnica no âmbito de serviços inerentes à Profissão de Biólogo. 1996. Disponível em: <http://www.cfbio.gov.br/artigos/RESOLUcaO-N\%C2\%BA-5-DE-2-DE-SETEMBRODE-1996>. Acesso em: 03 jul. 2018.

CONSELHO FEDERAL DE BIOLOGIA. Resolução CFBio no 7, de 11 de junho de 1999. Dispóe sobre as siglas CFBio e CRBio. Disponível em: <http://www.cfbio.gov.br/ artigos/RESOLUcaO-CFBio-N\%C2\%BA-07-DE-11-DE-JUNHO-DE-1999>. Acesso em: 05 ago. 2018.

CONSELHO FEDERAL DE BIOLOGIA. Resoluçáo CFBio no 11, de 05 de julho de 2003. Dispõe sobre a regulamentação para "Anotação de Responsabilidade Técnica - ART” por atividade profissional no âmbito das atividades inerentes à Profissão de Biólogo. 2003b. Disponível em: <http://www.cfbio.gov.br/artigos/RESOLUcaO-CFBioN\%C2\%BA-11-DE-05-DE-JULHO-DE-2003>. Acesso em: 05 ago. 2018.

CONSELHO FEDERAL DE BIOLOGIA. Resolução no 62, de 11 de junho de 2005. Fica criado o Conselho Regional de Biologia da 7a Região - CRBio-07, e dá outras providências. Disponível em: <http://crbio07.gov.br/images/inscricao/legislacaoresolucoes/62-2005.pdf> . Acesso em: 08 nov. 2018.

CONSELHO FEDERAL DE BIOLOGIA. Resoluçáo CFBio no 227, de 18 de agosto de 2010. Dispóe sobre a regulamentação das Atividades Profissionais e das Áreas de Atuação do Biólogo, em Meio Ambiente e Biodiversidade, Saúde e, Biotecnologia e Produção, para efeito de fiscalização do exercício profissional. 2010b. Disponível em: <http://www.cfbio.gov.br/artigos/RESOLUcaO-N\%C2\%BA-227-DE-18-DE-AGOSTODE-2010>. Acesso em: 05 ago. 2018.

CONSELHO FEDERAL DE BIOLOGIA. Resoluçáo CFBio no 284, de 20 de outubro de 2012. Estabelece os procedimentos de fiscalização no Sistema CFBio/CRBios, define competências e institui o Manual de Orientação e Fiscalização do Exercício Profissional. Disponível em: <http://www.cfbio.gov.br/artigo-imprimir.php?slug=RESOLUcaON\%C2\%BA-284-DE-20-DE-OUTUBRO-DE-2012>. Acesso em: 05 ago. 2018.

CONSELHO FEDERAL DE BIOLOGIA. Resolução CFBio no 350, de 10 de outubro de 2014. Dispóe sobre as diretrizes para a atuação do Biólogo em Licenciamento 
Ambiental. Disponível em: <http://www.cfbio.gov.br/artigos/RESOLUcaO-N\%C2\%BA350-DE-10-DE-OUTUBRO-DE-2014>. Acesso em: 15 nov. 2018.

CONSELHO FEDERAL DE BIOLOGIA. Resoluçáo CFBio no 374, de 12 de junho de 2015. 2015a. Dispóe sobre a atuação do Biólogo em Gestão Ambiental. Disponível em: <http://www.cfbio.gov.br/artigos/RESOLUcaO-N\%C2\%BA-374-DE-12-DEJUNHO-DE-2015>. Acesso em: 15 nov. 2018.

CONSELHO FEDERAL DE BIOLOGIA. Resoluçáo CFBio no 384, de 12 de dezembro de 2015. 2015b. Dispóe sobre a atuação do Biólogo no Controle de Vetores e Pragas Sinantrópicas. Disponível em: <http://www.cfbio.gov.br/artigos/RESOLUcaON\%C2\%BA-384-DE-12-DE-DEZEMBRO-DE-2015>. Acesso em 15 nov. 2018.

CONSELHO FEDERAL DE BIOLOGIA. Resoluçáo CFBio no 449, de 23 de outubro de 2017. Dispóe sobre as diretrizes para a atuação do Biólogo em Paisagismo. Disponível em: <http://www.cfbio.gov.br/artigos/RESOLUcaO-N\%C2\%BA-449-DE-23-DEOUTUBRO-DE-2017>. Acesso em: 15 nov. 2018.

CONSELHO REGIONAL DE BIOLOGIA (RS/SC). Quem somos. c2018. Disponível em: <https://www.crbio03.gov.br/index.php/institucional/quem-somos>. Acesso em: 08 nov. 2018

COSTA, Beatriz Rezende Marques; VALENTE, Manoel Adam Lacayo.

Responsabilidade social dos conselhos profissionais. Brasília: Câmara dos Deputados; Consultoria legislativa, 2008. (Estudo novembro/2008). Disponível em: <http://www2. camara.leg.br/a-camara/documentos-e-pesquisa/estudos-e-notas-tecnicas/areas-da-conle/ tema1/2008-14144.pdf>. Acesso em: 12 set. 2018.

GIL, Antonio Carlos. Como elaborar projetos de pesquisa. 4.ed. São Paulo: Atlas, 2002.

NEVES, Osías Ribeiro et al. Sistema CFBio/CRBios 30 anos: história e memórias. Brasília: Escritório de Histórias, 2011. 